\title{
Risk factors for 30-day reoperation and 3-month readmission: analysis from the Quality and Outcomes Database lumbar spine registry
}

\author{
Rishi K. Wadhwa, MD,1 Junichi Ohya, MD, ${ }^{1}$ Todd D. Vogel, MD, ${ }^{1}$ Leah Y. Carreon, MD, MSc, ${ }^{3}$ \\ Anthony L. Asher, MD, ${ }^{2}$ John J. Knightly, MD, ${ }^{4}$ Christopher I. Shaffrey, MD, ${ }^{5}$ \\ Steven D. Glassman, MD, ${ }^{3}$ and Praveen V. Mummaneni, MD ${ }^{1}$
}

'Department of Neurological Surgery, University of California, San Francisco, California; '2Department of Neurological Surgery, Carolinas Medical Center, Charlotte, North Carolina; ${ }^{3}$ Norton Leatherman Spine Center, Louisville, Kentucky; ${ }^{4}$ Atlantic Neurosurgical Specialists, Morristown, New Jersey; and ${ }^{5}$ Department of Neurological Surgery, University of Virginia Health System, Charlottesville, Virginia

OBJECTIVE The aim of this paper was to use a prospective, longitudinal, multicenter outcome registry of patients undergoing surgery for lumbar degenerative disease in order to assess the incidence and factors associated with 30-day reoperation and 90-day readmission.

METHODS Prospectively collected data from 9853 patients from the Quality and Outcomes Database (QOD; formerly known as the N2QOD [National Neurosurgery Quality and Outcomes Database]) lumbar spine registry were retrospectively analyzed. Multivariate binomial regression analysis was performed to identify factors associated with 30-day reoperation and 90-day readmission after surgery for lumbar degenerative disease. A subgroup analysis of Medicare patients stratified by age ( $<65$ and $\geq 65$ years old) was also performed. Continuous variables were compared using unpaired t-tests, and proportions were compared using Fisher's exact test.

RESULTS There was a $2 \%$ reoperation rate within 30 days. Multivariate analysis revealed prolonged operative time during the index case as the only independent factor associated with 30-day reoperation. Other factors such as preoperative diagnosis, body mass index (BMI), American Society of Anesthesiologists (ASA) class, diabetes, and use of spinal implants were not associated with reoperations within 30 days. Medicare patients $<65$ years had a 30 -day reoperation rate of $3.7 \%$, whereas those $\geq 65$ years had a 30 -day reoperation rate of $2.2 \%(p=0.026)$. Medicare beneficiaries younger than 65 years undergoing reoperation within 30 days were more likely to be women $(p=0.009)$, have a higher $\operatorname{BMI}(p=0.008)$, and have higher rates of depression $(p<0.0001)$. The 90 -day readmission rate was $6.3 \%$. Multivariate analysis demonstrated that higher ASA class (OR 1.46 per class, $95 \% \mathrm{Cl} 1.25-1.70$ ) and history of depression (OR 1.27, $95 \% \mathrm{Cl} 1.04-1.54$ ) were factors associated with 90 -day readmission. Medicare beneficiaries had a higher rate of $90-$ day readmissions compared with those who had private insurance (OR 1.43, 95\% Cl 1.17-1.76). Medicare patients $<65$ years of age were more likely to be readmitted within 90 days after their index surgery compared with those $\geq 65$ years $(10.8 \%$ vs $7.7 \%, p=0.017)$. Medicare patients $<65$ years of age had a significantly higher $\mathrm{BMI}(\mathrm{p}=0.001)$ and higher rates of depression ( $p<0.0001)$.

CONCLUSIONS In this analysis of a large prospective, multicenter registry of patients undergoing lumbar degenerative surgery, multivariate analysis revealed that prolonged operative time was associated with 30-day reoperation. The authors found that factors associated with 90-day readmission included higher ASA class and a history of depression. The 90-day readmission rates were higher for Medicare beneficiaries than for those who had private insurance. Medicare patients $<65$ years of age were more likely to undergo reoperation within 30 days and to be readmitted within 90 days after their index surgery.

https://thejns.org/doi/abs/10.3171/2016.12.SPINE16714

KEY WORDS lumbar spinal surgery; readmission; reoperation

ABBREVIATIONS ASA = American Society of Anesthesiologists; BMI = body mass index; EBL = estimated blood loss; NSQIP = National Surgical Quality Improvement Program; QOD = Quality and Outcomes Database.

SUBMITTED June 20, 2016. ACCEPTED December 30, 2016.

INCLUDE WHEN CITING Published online June 2, 2017; DOI: 10.3171/2016.12.SPINE16714. 
$\mathrm{O}$ VER the past 2 decades, the rate of spinal surgery to treat degenerative disease has grown in the aging population. ${ }^{10,22}$ Cost-containment is being sought in lumbar degenerative surgery to maintain financial sustainability. ${ }^{18}$ Short-term hospital readmissions after surgery are costly and have been scrutinized following the enactment of the Patient Protection and Affordable Care Act (PPACA) of 2010. ${ }^{12,14}$ The minimization of readmission-related expenses, of which Medicare paid nearly $\$ 17$ billion, is seen as a potential source of cost-containment. ${ }^{11}$ Payers including the Center for Medicare and Medicaid Services have been monitoring readmission to a hospital within 30 days after discharge from the index hospitalization. The Center for Medicare and Medicaid Services now collects and publishes readmissions through the Hospital Quality Alliance program. Medicare has sought to reduce payments to hospitals that have high readmission rates. ${ }^{8}$

Identifying factors associated with readmission following spine surgery has been problematic given previous limitations in the capacity of patient data collection. ${ }^{2,7}$, ${ }^{20,21}$ Previous studies have used retrospective, administrative data. These data are suspect, as has been documented by Goff et al. ${ }^{9}$ The authors demonstrated that one-third of patients with clinically documented congestive heart failure did not have the proper International Classification for Diseases (ICD) discharge code for heart failure. The Quality and Outcomes Database (QOD) was established to help benchmark cost-effectiveness in common neurosurgical procedures. ${ }^{3-5,17}$ The QOD registry can be used to help drive more cost-effective care as a basis for predicting which patients may be at high risk for additional expenditures. We sought to use the QOD registry to identify which clinical factors are associated with reoperation within 30 days and readmission within 90 days after lumbar spine surgery. We also aimed to assess if there were more readmissions and reoperations in the Medicare population stratified by age $(\geq 65$-year-old and $<65$-year-old subgroups of the Medicare covered population) than in the privately insured population. We suspected that younger patients with Medicare insurance may have unique medical comorbidities that increase their risk for 30-day reoperation or 90-day readmission compared with a cohort of similar age who had private insurance.

\section{Methods}

For this study, we queried data on patients in the QOD lumbar module from 37 participating centers. Multivariate binomial regression analysis was performed to identify risk factors for 30-day reoperation and 90-day readmission. Independent variables included in the analysis were age, sex, body mass index (BMI), educational level, American Society of Anesthesiologists (ASA) class, diagnosis, comorbidities (including diabetes mellitus, coronary artery disease, and depression), number of laminectomy levels, use of spinal implants, fusion surgery, operative time, and estimated blood loss (EBL).

We performed a subgroup analysis that compared Medicare beneficiaries stratified by age ( $\geq 65$ years and $<65$ years) who underwent a reoperation within 30 days or readmission within 90 days with the rationale that
TABLE 1. Patient demographic characteristics

\begin{tabular}{|c|c|}
\hline Variable & Value \\
\hline \multicolumn{2}{|l|}{ Insurance } \\
\hline Medicare & 3696 \\
\hline Private & 6156 \\
\hline Mean age in yrs & $54.2(16.7)$ \\
\hline \multicolumn{2}{|l|}{ Sex } \\
\hline Male & 5144 \\
\hline Female & 4704 \\
\hline Mean BMI in kg/m² & $30.3(6.3)$ \\
\hline Mean ASA class & $2.32(0.62)$ \\
\hline \multicolumn{2}{|l|}{ Education } \\
\hline$<$ High school & 519 \\
\hline High school or general educational development & 4118 \\
\hline 2 yrs college & 1765 \\
\hline 4 yrs college & 1958 \\
\hline Postgraduate & 1368 \\
\hline Diabetes mellitus & 1690 \\
\hline Coronary artery disease & 1116 \\
\hline Depression & 1942 \\
\hline \multicolumn{2}{|l|}{ Diagnosis } \\
\hline Lumbar disc herniation removal & 3598 \\
\hline Recurrent herniated disc removal & 550 \\
\hline Spondylolisthesis & 1919 \\
\hline Stenosis & 3243 \\
\hline Adjacent-segment degeneration & 452 \\
\hline Disc space collapse & 79 \\
\hline $\mathrm{EBL} \geq 250 \mathrm{ml}$ & 1511 \\
\hline Mean op length in mins & $120.3(78.2)$ \\
\hline Mean no. of laminectomies & $1.83(0.81)$ \\
\hline Fusion surgery & 3200 \\
\hline Use of implant & 3111 \\
\hline
\end{tabular}

Values are presented as the number of patients (\%) unless stated otherwise.

Mean values are presented as the mean (SD).

younger patients with Medicare insurance may have unique medical comorbidities that increase their risk for these outcomes. Continuous variables were compared using unpaired t-tests, and proportions were compared using Fisher's exact test. All statistical analyses were conducted using JMP Pro 11 (SAS Institute). The threshold for significance was $\mathrm{p}<0.05$.

\section{Results}

A total of 9852 patients were identified in the QOD lumbar registry database. The mean age of the cohort was 54.2 years (SD 16.7 years) with $5144(52.2 \%)$ men and 4704 (47.8\%) women. There were 3696 (37.5\%) Medicare beneficiaries and $6156(62.5 \%)$ with private medical insurance coverage (Table 1). Overall, 200 patients $(2.0 \%)$ returned to the operating room within 30 days and 616 patients $(6.3 \%)$ were readmitted within 90 days. Among Medicare beneficiaries, 92 patients (2.5\%) returned to the 
TABLE 2. Multivariate analysis of patients who underwent reoperation within 30 days

\begin{tabular}{lccc}
\hline & \multicolumn{3}{c}{ Return to Op Room } \\
\cline { 2 - 4 } \multicolumn{1}{c}{ Variable } & OR & $95 \%$ & $\mathrm{p}$ \\
$\mathrm{Cl}$ & Value \\
\hline Medicare insurance (reference: private) & 1.24 & $0.91-1.68$ & 0.169 \\
\hline BMI (every kg/m ${ }^{2}$ ) & 1.02 & $0.99-1.04$ & 0.149 \\
\hline ASA class (every 1 class) & 1.18 & $0.68-5.65$ & 0.214 \\
\hline DM (reference: no history) & 1.14 & $0.78-1.63$ & 0.490 \\
\hline Op length (every minute) & 1.002 & $1.0003-1.003$ & 0.021 \\
\hline Fusion surgery (reference: nonfusion) & 1.35 & $0.47-3.28$ & 0.556 \\
\hline Use of implant (reference: no implant) & 0.74 & $0.30-2.14$ & 0.558 \\
\hline
\end{tabular}

$\mathrm{DM}=$ diabetes mellitus.

operating room and 304 patients $(8.2 \%)$ were readmitted within 90 days. Medicare patients $<65$ years old were more likely to undergo a reoperation within 30 days $(3.7 \%$ vs $2.2 \%, \mathrm{p}=0.026$ ) and were more likely to be readmitted within 90 days $(10.8 \%$ vs $7.7 \%, \mathrm{p}=0.017)$ of their index surgery than those $\geq 65$ years old.

\section{Return to Operating Room Within 30 Days}

Table 2 shows the results of the multivariate analysis for return to the operating room within 30 days. Multivariate analysis revealed that prolonged operative time was independently associated with reoperation within 30 days (OR 1.002, 95\% CI 1.0003-1.003). Health insurance provider, BMI, ASA class, diabetes, fusion surgery, and use of implants were not significantly associated with a return to the operating room at 30 days in multivariate analysis.

Subgroup analysis of the patients with Medicare coverage (Table 3) who returned to surgery within 30 days showed that Medicare beneficiaries $<65$ years were more likely to undergo a reoperation than those $\geq 65$ years $(\mathrm{p}=$ $0.026)$. The younger Medicare patients were more likely to be female (70.8\% vs $39.7 \%$ ), have a BMI in the severely obese range $(50.0 \%$ vs $20.6 \%, \mathrm{p}=0.008)$, and have a history of depression (54.2\% vs $13.2 \%, \mathrm{p}<0.0001)$. We also found that Medicare beneficiaries $\geq 65$ years underwent laminectomy at more levels on average than those $<65$ years $(2.34$ vs $1.91, \mathrm{p}=0.048)$.

\section{Readmission Within 90 Days}

Table 4 shows the results of the analysis on 90-day readmissions. Multivariate analysis demonstrated that higher ASA class (OR 1.46 per grade, 95\% CI 1.25-1.70) and history of depression (OR 1.27, 95\% CI 1.04-1.54) were factors independently associated with 90-day readmission. In addition, we found that Medicare beneficiaries had a higher rate of 90-day readmissions than those those who had private insurance coverage (OR 1.43, 95\% CI 1.17-1.76).

Multivariate analysis demonstrated that Medicare beneficiaries had a higher rate of 90-day readmissions than patients with private insurance (OR 1.43, 95\% CI 1.171.76; $\mathrm{p}<0.001$ ) and those with a higher ASA class (OR 1.46 , 95\% CI 1.25-1.70; $\mathrm{p}<0.0001)$. In addition, multi-
TABLE 3. Subgroup analysis of patients undergoing reoperation within 30 days who had Medicare insurance coverage, stratified by age

\begin{tabular}{|c|c|c|c|}
\hline Variable & $\geq 65 \mathrm{Yrs}$ & $<65$ Yrs & $p$ Value \\
\hline Total (\%) & $68 / 3053(2.2 \%)$ & $24 / 643(3.7 \%)$ & 0.026 \\
\hline Sex & & & 0.009 \\
\hline Male & $41(60.3 \%)$ & $7(29.2 \%)$ & \\
\hline Female & $27(39.7 \%)$ & $17(70.8 \%)$ & \\
\hline $\mathrm{BMI}$ in $\mathrm{kg} / \mathrm{m}^{2}$ & & & 0.008 \\
\hline$<25$ & $11(16.2 \%)$ & $0(0.0 \%)$ & \\
\hline $25-30$ & $23(33.8 \%)$ & $7(29.2 \%)$ & \\
\hline $30-35$ & $20(29.4 \%)$ & $4(16.7 \%)$ & \\
\hline$\geq 35$ & $14(20.6 \%)$ & $13(54.2 \%)$ & \\
\hline Mean ASA class & $2.68(0.59)$ & $2.79(0.51)$ & 0.401 \\
\hline DM & & & 0.382 \\
\hline Yes & $19(27.9 \%)$ & $9(37.5 \%)$ & \\
\hline No & $49(72.1 \%)$ & $15(62.5 \%)$ & \\
\hline CAD & & & 0.202 \\
\hline Yes & $17(25.0 \%)$ & $3(12.5 \%)$ & \\
\hline No & $51(75.0 \%)$ & $21(87.5 \%)$ & \\
\hline Depression & & & $<0.0001$ \\
\hline Yes & $9(13.2 \%)$ & $13(54.2 \%)$ & \\
\hline No & $59(86.8 \%)$ & $11(45.8 \%)$ & \\
\hline $\mathrm{EBL}(\mathrm{ml})$ & & & 0.971 \\
\hline$<250$ & $36(65.5 \%)$ & $13(65.0 \%)$ & \\
\hline$\geq 250$ & $19(34.6 \%)$ & $7(35.0 \%)$ & \\
\hline Mean op length in mins & $156.2(107.4)$ & $153.5(84.4)$ & 0.901 \\
\hline $\begin{array}{l}\text { Mean no. of laminec- } \\
\text { tomy levels }\end{array}$ & $2.34(0.84)$ & $1.91(1.00)$ & 0.048 \\
\hline Fusion surgery & & & 0.283 \\
\hline Yes & $31(45.6 \%)$ & $14(58.3 \%)$ & \\
\hline No & $37(54.4 \%)$ & $10(41.7 \%)$ & \\
\hline Use of implant & & & 0.330 \\
\hline Yes & $29(42.6 \%)$ & $13(54.2 \%)$ & \\
\hline No & $39(57.4 \%)$ & $11(45.8 \%)$ & \\
\hline
\end{tabular}

$\mathrm{CAD}=$ coronary artery disease.

variate analysis demonstrated that a history of depression (OR 1.27, 95\% CI 1.04-1.54, $\mathrm{p}=0.018$ ) was independently associated with 90-day readmission.

Subgroup analysis of the Medicare population (Table 5) showed findings similar to those of reoperation at 30 days. A greater proportion of younger Medicare patients were severely obese with a BMI $\geq 35(35.3 \%$ vs $16.2 \%$, $\mathrm{p}=$ $0.001)$, history of depression $(54.4 \%$ vs $19.5 \%, \mathrm{p}<0.0001)$, and underwent fusion surgery $(55.9 \%$ vs $37.7 \%, p=0.007)$. Elderly Medicare patients underwent laminectomy at more levels (mean 2.05 vs $1.78, \mathrm{p}=0.027$ ) and had a higher rate of coronary artery disease $(26.7 \%$ vs $11.8 \%, \mathrm{p}=0.010)$.

\section{Discussion}

To our knowledge, this is the first prospective analysis for readmission and reoperation rates in lumbar surgery 
TABLE 4. Multivariate analysis of patients readmitted within 90 days

\begin{tabular}{lccc}
\hline \multirow{2}{*}{ Variable } & \multicolumn{3}{c}{ Readmission } \\
\cline { 2 - 4 } & OR & $95 \% \mathrm{Cl}$ & $\mathrm{p}$ Value \\
\hline Medicare (reference: private) & 1.43 & $1.17-1.76$ & $<0.001$ \\
\hline Age (every 1 yr) & 1.00 & $0.99-1.004$ & 0.784 \\
\hline ASA class (every 1 class) & 1.46 & $1.25-1.70$ & $<0.0001$ \\
\hline DM (reference: no history) & 1.07 & $0.86-1.32$ & 0.532 \\
\hline CAD (reference: no history) & 1.05 & $0.81-1.33$ & 0.725 \\
\hline Depression (reference: no history) & 1.27 & $1.04-1.54$ & 0.018 \\
\hline
\end{tabular}

utilizing a multiinstitutional registry. Previous studies have looked at a retrospective Medicare cohort to evaluate 30-day readmission rates. This retrospective study by Wang et al. ${ }^{21}$ in which Medicare claims data were used demonstrated a readmission rate of $7.3 \%$ after lumbar surgery. The most common reasons for readmission were complications related to surgery and musculoskeletal conditions. Predictors for readmission included black race, increasing age, greater comorbidity, Medicare/Medicaid eligibility, anterior approach, fusion surgery versus decompression alone, and the number of levels fused. Major limitations of that study include using administrative data (which is sometimes inaccurate as demonstrated by Amin et al. $^{2}$ ) and collecting it in a retrospective fashion. Moreover, Wang et al. did not include patients outside of the Medicare population.

Modhia et al. published a comparison of Medicare beneficiaries with lumbar spine stenosis who underwent decompression with fusion and those who underwent decompression alone and demonstrated higher 1- and 2-year readmission rates in the patients undergoing decompression with fusion. ${ }^{19}$ They reported $9.7 \%$ and $7.3 \%$ readmission rates at 1 year and $14.6 \%$ and $12.5 \%$ at 2 years, respectively. After readmission, $56 \%$ of patients later underwent additional fusion procedures, $23 \%$ had additional decompression, and $22 \%$ had injections for pain management. Modhia et al. concluded that fusion does not appear to impact readmission rates, which is similar to our findings.

McCormack et al. reported a single-center retrospective chart review of their own readmission rates following decompression with or without fusion for lumbar spinal stenosis. ${ }^{16}$ They noted a $3.8 \%$ unplanned readmission rate with higher rates for increasing age, for number of comorbidities, for those who underwent more complex fusions, and for those in whom more levels were fused. The most common cause for readmission was infection or concern for infection followed by nonsurgical complications and then hardware complications. They did note that a major limitation of their study is that they were only able to review readmissions at their own facility.

Kim and colleagues queried the National Surgical Quality Improvement Program (NSQIP) to identify risk factors for 30-day readmission in patients undergoing lumbar decompression using a risk-adjusted multivariate logistic regression analysis. ${ }^{15}$ They demonstrated that anemia, dependent functional status, total operative dura-
TABLE 5. Subgroup analysis of patients readmitted within 90 days who had Medicare insurance coverage, stratified by age

\begin{tabular}{|c|c|c|c|}
\hline Variable & $\geq 65 \mathrm{Yrs}$ & $<65 \mathrm{Yrs}$ & $p$ Value \\
\hline Total & $236 / 3053(7.7 \%)$ & $68 / 643(10.6 \%)$ & 0.017 \\
\hline Sex & & & 0.328 \\
\hline Male & $120(50.8 \%)$ & $30(44.1 \%)$ & \\
\hline Female & $116(49.2 \%)$ & $38(55.9 \%)$ & \\
\hline BMI $\left(\mathrm{kg} / \mathrm{m}^{2}\right)$ & & & 0.001 \\
\hline$<25$ & $49(20.9 \%)$ & $6(8.8 \%)$ & \\
\hline $25-30$ & $91(38.7 \%)$ & $19(27.9 \%)$ & \\
\hline $30-35$ & $57(24.3 \%)$ & $19(27.9 \%)$ & \\
\hline$\geq 35$ & $38(16.2 \%)$ & $24(35.3 \%)$ & \\
\hline Mean ASA class & $2.72(0.54)$ & $2.71(0.52)$ & 0.839 \\
\hline DM & & & 0.590 \\
\hline Yes & $65(27.5 \%)$ & $21(30.9 \%)$ & \\
\hline No & $171(72.5 \%)$ & $47(69.1 \%)$ & \\
\hline CAD & & & 0.010 \\
\hline Yes & $63(26.7 \%)$ & $8(11.8 \%)$ & \\
\hline No & $173(73.3 \%)$ & $60(88.2 \%)$ & \\
\hline Depression & & & $<0.0001$ \\
\hline Yes & $46(19.5 \%)$ & $37(54.4 \%)$ & \\
\hline No & $190(80.5 \%)$ & $31(45.6 \%)$ & \\
\hline $\mathrm{EBL}(\mathrm{ml})$ & & & 0.078 \\
\hline$<250$ & $143(73.3 \%)$ & $29(60.4 \%)$ & \\
\hline$\geq 250$ & $52(26.7 \%)$ & $19(40.0 \%)$ & \\
\hline Mean op length in mins & $128.6(73.7)$ & $146.1(96.5)$ & 0.110 \\
\hline $\begin{array}{l}\text { Mean no. of laminec- } \\
\text { tomy levels }\end{array}$ & $2.05(0.84)$ & $1.78(0.83)$ & 0.027 \\
\hline Fusion surgery & & & 0.007 \\
\hline Yes & $89(37.7 \%)$ & $38(55.9 \%)$ & \\
\hline No & $147(62.3 \%)$ & $30(44.1 \%)$ & \\
\hline Use of implant & & & 0.015 \\
\hline Yes & $83(35.2 \%)$ & $35(51.5 \%)$ & \\
\hline No & $153(64.8 \%)$ & $33(48.5 \%)$ & \\
\hline
\end{tabular}

tion, and ASA Class IV were independent predictors of unplanned readmission. Moreover, postoperative complications including unplanned reoperation and pulmonary embolism were significantly associated with unplanned readmission. Basques et al. also queried the NSQIP database and found increased age, increased BMI, ASA Classes III and IV, and steroid use were independent risk factors for readmission following laminectomy for lumbar spinal stenosis. ${ }^{6}$ They did note that a preoperative hematocrit level less than 36 contributed to longer length of stay but did not appear to affect readmission, as Kim et al. identified. ${ }^{15}$ Surgical site infection was the most common indication for readmission. Joynt et al. demonstrated that variability of 30-day readmission rates might be the composition of a hospital's patient population and resources of the community in which it is located..$^{13}$

In this study, we demonstrated that a higher return to the operating room at 30 days was associated with longer operative time during the index surgery. Although the 
odds ratio may appear relatively small, the operative time is measured in minutes. Thus, the cumulative odds ratio with longer operative times may be clinically significant. This issue was also identified as a risk factor for readmission but not return to the operating room in the NSQIP data analysis. Medicare patients were significantly more likely to be readmitted at 90 days than privately insured patients. This did not appear to be dependent on age in multivariate analysis. Similar to the NSQIP data, ${ }^{15}$ patients in higher ASA classes were also more likely to be readmitted within 90 days.

The $8.2 \%$ readmission rate for Medicare beneficiaries in this study is slightly higher than the $7.2 \%$ reported by Wang et al. ${ }^{21}$ Moreover, the overall readmission rate of $6.3 \%$ from the QOD database was greater than the $4.2 \%$ reported by Kim et al..$^{15}$ from the NSQIP database. We believe that this is a reflection of a longer window for readmission of 90 days in this study compared with the 30-day readmission rates that they reported.

One limitation of the QOD is that the comorbidities are extracted in a dichotomous fashion. This is of particular interest in regard to depression. Depression was a significant factor for readmission at 90 days. However, the QOD database collects only a history of depression. The new Diagnostic and Statistical Manual of Mental Disorders, Fifth Edition (DSM-5) now lists 8 subtypes of depression diagnoses. ${ }^{1}$ The QOD does not have the sensitivity to delineate between these subtypes and their ongoing treatment. Thus, depression may represent a diagnosis that could be screened for and treated as a modifiable risk factor in the future.

One important facet to note is that this QOD study is a retrospective analysis of prospectively collected registry data, whereas prior published studies on this topic have been purely retrospective. It is important to note that Medicare patients $<65$ years old constituted a subgroup that was significantly more likely to undergo reoperation within 30 days and to be readmitted within 90 days following their index surgery. These patients had a higher preoperative BMI and higher preoperative rates of depression. Patients $<65$ years typically have significant medical issues that allow for Medicare eligibility, and we found a correlation for these younger Medicare-insured patients with higher readmission and reoperation rates after lumbar surgery than other patient populations. This is important to note in an era in which physicians and hospitals are compared with respect to quality benchmarks for readmission and reoperation rates. Physicians and hospitals that treat a greater proportion of this patient population may have higher reoperation and readmission rates.

\section{Conclusions}

In this retrospective analysis of a large prospectively collected, multicenter registry of patients undergoing lumbar degenerative surgery, multivariate analysis revealed that 30-day reoperation was associated with prolonged operative time. We found that 90 -day readmission was associated with higher ASA class and a history of depression. The 90-day readmission rates were higher for Medicare beneficiaries than for those who had private insurance coverage. Factors associated with 90-day readmissions included higher ASA class and a history of depression. Medicare patients younger than 65 years old were significantly more likely to undergo reoperation within 30 days and to be readmitted within 90 days after their index surgery. These patients had higher preoperative BMI and higher preoperative rates of depression. Understanding realistic rates of readmission and reoperation of patient subgroups is needed in the era of quality benchmarking of physicians and hospitals.

\section{References}

1. American Psychiatric Association: Diagnostic and Statistical Manual of Mental Disorders, ed 5. Washington, D.C.: American Psychiatric Association, 2013

2. Amin BY, Tu TH, Schairer WW, Na L, Takemoto S, Berven $\mathrm{S}$, et al: Pitfalls of calculating hospital readmission rates based on nonvalidated administrative data sets: presented at the 2012 Joint Spine Section Meeting: clinical article. J Neurosurg Spine 18:134-138, 2013

3. Asher AL, McCormick PC, Selden NR, Ghogawala Z, McGirt MJ: The National Neurosurgery Quality and Outcomes Database and NeuroPoint Alliance: rationale, development, and implementation. Neurosurg Focus 34(1):E2, 2013

4. Asher AL, McGirt MJ, Glassman SD, Groman R, Resnick DK, Mehrlich M, et al: Regulatory considerations for prospective patient care registries: lessons learned from the National Neurosurgery Quality and Outcomes Database. Neurosurg Focus 34(1):E5, 2013

5. Asher AL, Speroff T, Dittus RS, Parker SL, Davies JM, Selden N, et al: The National Neurosurgery Quality and Outcomes Database (N²QOD): a collaborative North American outcomes registry to advance value-based spine care. Spine (Phila Pa 1976) 39 (22 Suppl 1):S106-S116, 2014

6. Basques BA, Varthi AG, Golinvaux NS, Bohl DD, Grauer JN: Patient characteristics associated with increased postoperative length of stay and readmission after elective laminectomy for lumbar spinal stenosis. Spine (Phila Pa 1976) 39:833-840, 2014

7. Copertino LM, McCormack JE, Rutigliano DN, Huang EC, Shapiro MJ, Vosswinkel JA, et al: Early unplanned hospital readmission after acute traumatic injury: the experience at a state-designated level-I trauma center. Am J Surg 209:268273,2015

8. Epstein AM: Revisiting readmissions-changing the incentives for shared accountability. N Engl J Med 360:14571459, 2009

9. Goff DC Jr, Pandey DK, Chan FA, Ortiz C, Nichaman MZ: Congestive heart failure in the United States: is there more than meets the I(CD code)? The Corpus Christi Heart Project. Arch Intern Med 160:197-202, 2000

10. Gray DT, Deyo RA, Kreuter W, Mirza SK, Heagerty PJ, Comstock BA, et al: Population-based trends in volumes and rates of ambulatory lumbar spine surgery. Spine (Phila Pa 1976) 31:1957-1964, 2006

11. Jencks SF, Williams MV, Coleman EA: Rehospitalizations among patients in the Medicare fee-for-service program. $\mathbf{N}$ Engl J Med 360:1418-1428, 2009

12. Jha AK, Orav EJ, Epstein AM: Public reporting of discharge planning and rates of readmissions. N Engl J Med 361:2637-2645, 2009

13. Joynt KE, Orav EJ, Jha AK: Thirty-day readmission rates for Medicare beneficiaries by race and site of care. JAMA 305:675-681, 2011

14. Kansagara D, Englander H, Salanitro A, Kagen D, Theobald C, Freeman M, et al: Risk prediction models for hospital readmission: a systematic review. JAMA 306:1688-1698, 2011 
15. Kim BD, Smith TR, Lim S, Cybulski GR, Kim JY: Predictors of unplanned readmission in patients undergoing lumbar decompression: multi-institutional analysis of 7016 patients. J Neurosurg Spine 20:606-616, 2014

16. McCormack RA, Hunter T, Ramos N, Michels R, Hutzler L, Bosco JA: An analysis of causes of readmission after spine surgery. Spine (Phila Pa 1976) 37:1260-1266, 2012

17. McGirt MJ, Speroff T, Dittus RS, Harrell FE Jr, Asher AL: The National Neurosurgery Quality and Outcomes Database $\left(\mathrm{N}^{2} \mathrm{QOD}\right)$ : general overview and pilot-year project description. Neurosurg Focus 34(1):E6, 2013

18. Missios S, Bekelis K: Hospitalization cost after spine surgery in the United States of America. J Clin Neurosci 22:16321637,2015

19. Modhia U, Takemoto S, Braid-Forbes MJ, Weber M, Berven SH: Readmission rates after decompression surgery in patients with lumbar spinal stenosis among Medicare beneficiaries. Spine (Phila Pa 1976) 38:591-596, 2013

20. Singh S, Sparapani R, Wang MC: 164 Should spine surgeons be held accountable for 30-day readmissions? Neurosurgery 62 (1 Suppl):219-220, 2015 (Abstract)

21. Wang MC, Shivakoti M, Sparapani RA, Guo C, Laud PW, Nattinger AB: Thirty-day readmissions after elective spine surgery for degenerative conditions among US Medicare beneficiaries. Spine J 12:902-911, 2012

22. Weinstein JN, Lurie JD, Olson PR, Bronner KK, Fisher ES: United States' trends and regional variations in lumbar spine surgery: 1992-2003. Spine (Phila Pa 1976) 31:2707-2714, 2006

\section{Disclosures}

The authors report the following. Dr. Carreon: employee of Norton Healthcare; consultant for AOSpine, Washington University; non-study-related support from Norton Healthcare, AOSpine, OREF, and SR; travel funds from the University of Louisville and the University of Southern Denmark; member of the editorial advisory boards of Spine and Spine Journal, University of Louisville IRB, SRS Research Committee; and funds from NuVasive directly to the database company. Dr. Shaffrey: consultant for Zimmer Biomet, Medtronic, NuVasive, and Stryker; direct stock ownership in NuVasive; patent holder with Zimmer Biomet, Medtronic, and NuVasive; and non-study-related support from DePuy Synthes. Dr. Glassman: employee of Norton Healthcare; patent holder with, consultant for, and royalties from Medtronic; past president of the Scoliosis Research Society. Dr. Mummaneni: consultant for DePuy Spine; direct stock ownership in Spinicity/ ISD; royalties from DePuy Spine, Springer Publishing, Taylor and Francis Publishers, and Thieme Publishing; and honoraria and grant from AOSpine.

\section{Author Contributions}

Conception and design: Wadhwa, Asher, Mummaneni. Acquisition of data: Vogel, Knightly. Analysis and interpretation of data: Wadhwa, Ohya, Shaffrey, Glassman, Mummaneni. Drafting the article: Ohya. Critically revising the article: Ohya, Vogel, Carreon, Asher, Knightly, Shaffrey, Glassman, Mummaneni. Reviewed submitted version of manuscript: Vogel, Carreon, Asher, Mummaneni. Approved the final version of the manuscript on behalf of all authors: Wadhwa. Statistical analysis: Wadhwa, Carreon. Administrative/technical/material support: Wadhwa, Mummaneni. Study supervision: Shaffrey, Mummaneni.

\section{Supplemental Information Previous Presentations}

This work was presented in oral form at the 2016 AANS Annual Scientific Meeting, May 2-4, 2016, Chicago, IL.

\section{Correspondence}

Rishi Wadhwa, Department of Neurological Surgery, University of California, San Francisco, 505 Parnassus Ave., M780, San Francisco, CA 94143. email: wadhwar@neurosurg.ucsf.edu. 